\title{
HIGHER SERUM LEVELS OF VITAMIN D ARE ASSOCIATED WITH LOWER BLOOD GLUCOSE LEVELS
}

\author{
Valladares Andriolli, Tania; Aldrighi, José Mendes. \\ University of Sao Paulo School of Public Health - Sao Paulo, Brazil
}

Problem statement: Despite Vitamin D important role in bone metabolism, evidences suggest that higher serum levels of 25(OH)D might be associated with a lower risk of developing type 2 diabetes mellitus, possibly by providing better glycemic control. The objective of the present study was to evaluate the possible association between 25(OH)D sufficiency and glycemia.

Methods: This was a cross-sectional study in Brazil, involving 681 women aged 35 to 74 years, selected through systematic sampling applied to a sampling frame comprising 7,212 women enrolled in a Family Health Program. The study was approved by the Research Ethics Committee of the University of São Paulo School of Public Health. All participants gave written consent.

Participant were interviewed and had fasting blood samples collected on scheduled dates. Data were stored in a Microsoft Access 2003 database and were analyzed with the Stata statistical software package, version 11.0 (StataCorp LP, College Station, TX). Total $25(\mathrm{OH}) \mathrm{D}$ was categorized as $\geq$ $30 \mathrm{ng} / \mathrm{mL}$ versus $<30 \mathrm{ng} / \mathrm{mL}$, and as $\geq 20 \mathrm{ng} / \mathrm{mL}$ versus $<20 \mathrm{ng} / \mathrm{mL}$. Blood glucose levels were categorized as $<100 \mathrm{mg} / \mathrm{dL}$ versus $\geq 100 \mathrm{mg} / \mathrm{dL}$.
Results: The mean fasting blood glucose and 25(OH)D levels was $105 \mathrm{mg} / \mathrm{dL}$ (range, 26-401 $\mathrm{mg} / \mathrm{dL}$ ) and $26.4 \mathrm{ng} / \mathrm{mL}$ (range, 5.8-55.9 $\mathrm{ng} / \mathrm{mL}$ ), respectively. The prevalence of a serum $25(\mathrm{OH}) \mathrm{D}$ level $<20 \mathrm{ng} / \mathrm{mL}$ was $26.6 \%$ (95\% Cl 23.3\%-29.9\%) and that of a serum $25(\mathrm{OH}) \mathrm{D}$ level $<30 \mathrm{ng} / \mathrm{mL}$ was $65.4 \%$ (95\% Cl 61.6\%-68.7\%).

A serum 25(OH)D level $\geq 30 \mathrm{ng} / \mathrm{mL}$ was found to be negatively associated to blood glucose level $\geq 100 \mathrm{mg} / \mathrm{dL}$ (OR $=0.62 ; 95 \% \mathrm{Cl}, 0.44-0.85$ ), as was a serum 25(OH)D level $\geq 20 \mathrm{ng} / \mathrm{mL}$ (OR=0.68, 95\% Cl, 0.48-0.95). In the multivariate Poisson analysis, considering body mass index, age, and systolic blood pressure, a blood glucose level $\geq 100 \mathrm{mg} / \mathrm{dL}$ maintained its associations with serum $25(\mathrm{OH})$ D levels $<20 \mathrm{ng} / \mathrm{mL}$ and $<30 \mathrm{ng} / \mathrm{mL}$ (Table 1).

Conclusions: In the present study, higher serum 25(OH)D concentrations was associated with blood glucose levels lower than $100 \mathrm{mg} / \mathrm{dL}$.

Disclosure of Interest: In Brazil, it was found a positive association between lower vitamin $D$ concentrations and glucose levels higher than $100 \mathrm{mg} / \mathrm{dL}$.

\begin{tabular}{|l|c|c|c|c|c|c|}
\hline \multirow{2}{*}{} & \multicolumn{6}{|c|}{ Serum 25(OH)D level } \\
\cline { 2 - 7 } & \multicolumn{5}{|c|}{$\geq 20 \mathrm{ng} / \mathrm{mL}$} & \multicolumn{3}{c|}{$\geq 30 \mathrm{ng} / \mathrm{mL}$} \\
\cline { 2 - 7 } Variable & $\mathrm{OR}$ & $\mathrm{P}$ & $95 \% \mathrm{Cl}$ & $\mathrm{OR}$ & $\mathrm{P}$ & $95 \% \mathrm{Cl}$ \\
\hline Glycemia $\geq \mathbf{1 0 0} \mathbf{~ m g / d L}$ & $\mathbf{0 . 9 0}$ & $\mathbf{0 . 0 3 1}$ & $\mathbf{0 . 8 1 - 0 . 9 9 *}$ & $\mathbf{0 . 7 5}$ & $\mathbf{0 . 0 1 7}$ & $\mathbf{0 . 6 0 - 0 . 9 5 *}$ \\
\hline $\mathrm{BMI} \geq 30 \mathrm{~kg} / \mathrm{m}^{2}$ & 1.03 & 0.471 & $0.94-1.14$ & 0.91 & 0.413 & $0.73-1.14$ \\
\hline Age $\geq 60$ years & 1.06 & 0.213 & $0.96-1.19$ & 0.95 & 0.679 & $0.73-1.23$ \\
\hline
\end{tabular}

